\title{
PARAMETER POPULASI DAN BIOLOGI REPRODUKSI IKAN BENTONG (Selar crumenophthalmus) DI PERAIRAN KWANDANG, GORONTALO UTARA
}

\section{POPULATION AND REPRODUCTIVE BIOLOGY PARAMETERS OF BIGEYE SCAD (Selar crumenophthalmus) IN THE KWANDANG WATERS, NORTH GORONTALO}

\author{
Ria Faizah $^{1}$, Lilis Sadiyah ${ }^{1}$ dan Tuti Hariati ${ }^{2}$ \\ ${ }^{1}$ Peneliti Pada Pusat Penelitian Pengelolaan Perikanan dan Konservasi Sumber Daya Ikan \\ ${ }^{2}$ Peneliti pada Balai Penelitian Perikanan Laut-Muara Baru \\ Teregistrasi I tanggal: 27 Maret 2014; Diterima setelah perbaikan tanggal: 08 Agustus 2014; \\ Disetujui terbit tanggal: 12 Agustus 2014 \\ E-mail: faizah_ria@yahoo.com
}

\begin{abstract}
ABSTRAK
Perairan Kwandang merupakan salah satu basis utama perikanan pelagis kecil di perairan laut Sulawesi. Salah satu jenis yang banyak dimanfaatkan adalah ikan bentong (Selar crumenophthalmus). Penelitian ini bertujuan untuk menduga parameter populasi, tingkat pemanfaatan (E), dan biologi reproduksi dari ikan bentong.. Data panjang cagak dikumpulkan dari PP Kwandang dari bulan Januari hingga November 2012. Pendugaan parameter populasi dilakukan dengan menggunakan metode Bhattacharya dengan bantuan software FISAT II Hasil analisis menunjukkan bahwa laju pertumbuhan $(\mathrm{K})$ sebesar 0,76 per tahun dengan L" $=24,7 \mathrm{~cm}$. Laju kematian total (Z) sebesar 2,63 per tahun, dengan laju kematian alamiah (M) sebesar 1,28 per tahun, laju kematian akibat penangkapan (F) sebesar 1,3 per tahun dan laju pemanfaatan 0,51. Tingkat pemanfaatan ikan bentong sudah relatif optimum. Rasio jenis kelamin ikan bentong jantan dan betina adalah 1: 1,02. TKG I paling banyak ditemukan. Musim pemijahan ikan bentong diduga terjadi pada bulan November dan Desember.
\end{abstract}

Kata Kunci : Ikan bentong, parameter populasi, biologi, Kwandang

\section{ABSTRACT}

The Kwandang waters is one of the main base for small pelagic fisheries in Sulawesi sea. Bigeye scad (Selar crumenophthalmus) is one of species from small pelagic is exploited. The objectives of the research was to estimate the population parameters, exploitation rate and reproductive biology of bigeye scad. Length frequency data were collected from PP Kwandang, from January-November 2012. Estimation of population parameters of bigeye scad used FISAT II method. The results showed that growth rate as follows $(K)=0,76$ year ${ }^{-1}, L^{\prime \prime}=24,7$ $\mathrm{cm}$. Total mortality rate $(Z)=2,63$ year $^{-1}$, with natural mortality $(M)=1$, year ${ }^{-1}$ and fishing mortality $(F)=1,3$ year ${ }^{-1}$ and exploitation rate $(E)=0,51$. The exploitation rate are already optimum. Sex ratio of male and female are 1:1,02. The most commonly founded is Gonado Maturity Stage of I. The spawning season of bigeye scad estimated was November and December

Keyword : Bigeye scad, population parameter, biology, Kwandang

\section{PENDAHULUAN}

Perairan laut Sulawesi memiliki sumberdaya ikan pelagis kecil yang merupakan komoditi bernilai ekonomis penting. Perikanan pelagis kecil di laut Sulawesi didaratkan di Tumumpa, Bitung, Minahasa Utara dan Kwandang-Gorontalo Utara. Pelabuhan Perikanan Kwandang merupakan salah satu pusat kegiatan perikanan tangkap di Kabupaten Gorontalo Utara (Gorut) dan sejak awal tahun 2011 telah memiliki Pelabuhan Perikanan (PP) Kwandang di tepian Laut Sulawesi. PP Kwandang merupakan basis utama perikanan pelagis kecil dan perikanan pelagis besar. Ikan pelagis kecil yang dominan tertangkap dari perairan Gorontalo Utara kurang lebih berjumlah 6 jenis yaitu ikan layang (Decapterus spp., terdiri dari 3 spesies), ikan banyar/kembung lelaki
(Rastrelliger kanagurta), selar/bentong (Selar crumenophthalmus), ikan teri (Stolephorus spp) terdiri dari 2 spesies, ikan siro/lemuru (Ambligaster sirm) dan ikan tembang (Sardinella spp.). Ikan-ikan tersebut tertangkap dengan alat tangkap pukat cincin/pajeko, jaring insang (gillnet), bagan apung, pancing dan payang/pajala. Menurut Suwarso et al, 2013 pemanfaatan ikan pelagis di perairan Laut Sulawesi mengalami peningkatan peningkatan dari tahun ke tahun. Hal ini dikhawatirkan akan mengancam keberlangsungan dari ikan pelagis kecil di perairan ini.

Informasi mengenai sumberdaya ikan pelagis kecil terutama ikan bentong di perairan Kwandang masih sangat jarang dibandingkan dengan di perairan laut Jawa, seperti yang pernah dilakukan oleh Atmaja et al (1995) 


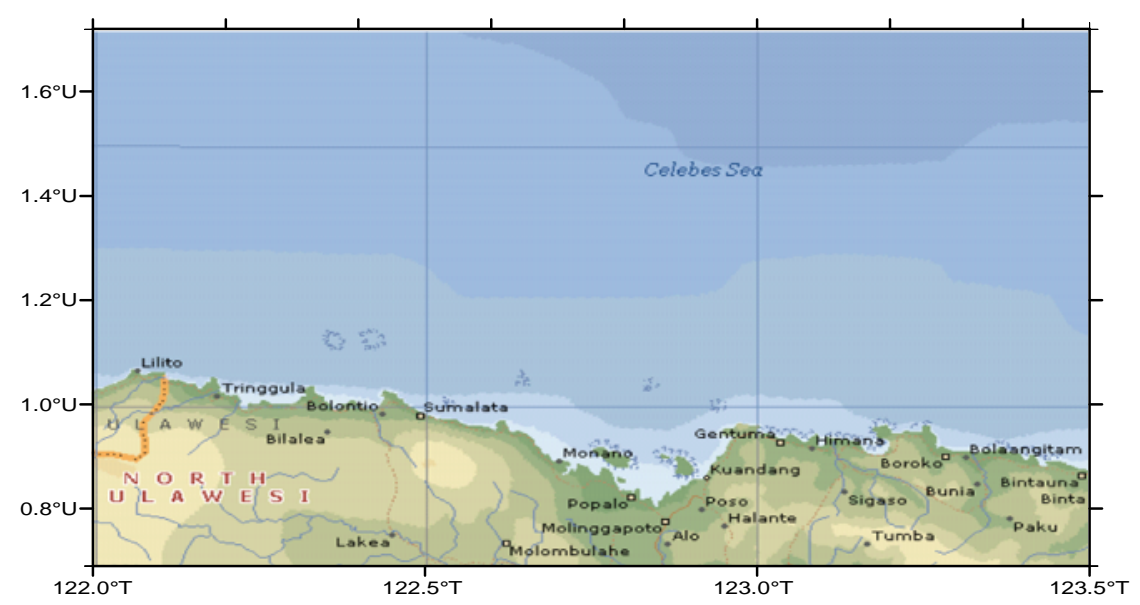

Gambar 1. Peta Lokasi Penelitian di Kwandang Gorontalo Utara.

Figure 1. Map showing of the study in Kwandang-North Gorontalo.

tentang beberapa sifat yang berkaitan dengan aspek reproduksinya. Oleh karena itu perlu dilakukan penelitian mengenai sumberdaya ini di perairan Kwandang yang meliputi parameter populasi, tingkat pemanfaatan (E), dan biologi reproduksi. Tulisan ini bertujuan untuk memperoleh gambaran parameter pertumbuhan dan biologi reproduksi ikan di Perairan Kwandang Gorontalo Utara.

\section{BAHANDANMETODE}

\section{Waktu, Lokasi dan Jenis Data}

Penelitian dilakukan di Pelabuhan Perikanan Pantai Kwandang Gorontalo Utara pada Januari-November 2012. Data yang dikumpulkan adalah sebaran frekwensi panjang ikan setiap bulannya.

\section{Prosedur Pengambilan Sampel}

Pengukuran frekuensi panjang ikan dilakukan selama periode bulan Januari, Februari, Maret, Juni, Agustus dan November 2012. Sejumlah sampel ikan bentong (Selar crumenophthalmus) hasil tangkapan bagan diperoleh secara acak, kemudian masing-masing sampel diukur panjang cagaknya (FL) menggunakan kertas ukur khusus dengan ketelitian $0,5 \mathrm{~cm}$.

\section{Analisis Data}

\section{a. Parameter pertumbuhan}

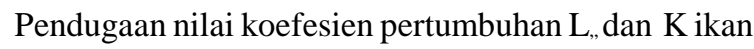
bentong diolah dari data pergeseran modus sebaran frekuensi panjang cagak dalam satu runut waktu menggunakan kurva pertumbuhan von Bertalanffy. Selanjutnya kurva yang melalui modus paling banyak akan menggambarkan pola pertumbuhan (Sparre \& Venema, 1999). Pendugaan parameter ini menggunakan software
FISAT II (2004). sedangkan $\mathrm{t}_{0}$ diperoleh melalui persamaan Pauly (1980), yaitu :

$\log (-$ to $)=0,3922-0,2752 \log (\mathrm{L})-1.038 \log (\mathrm{K})$

Model pertumbuhan yang digunakan adalah model yang dikemukakan oleh Von Bertalanffy (Sparre dan Venema, 1999) dengan persamaan sebagai berikut:

$\mathrm{L}_{\mathrm{t}}=L \infty\left(1-\mathrm{e}^{-\mathrm{k}(\mathrm{t}-\mathrm{to})}\right)$

dimana :

$\mathrm{Lt}=$ Panjang ikan $(\mathrm{cm})$ pada umur $\mathrm{t}$ (tahun)

$L \infty=$ Panjang asimptot ikan $(\mathrm{cm})$

$\mathrm{K}=$ Koefisien pertumbuhan (per tahun)

to = Umur teoritis ikan pada saat panjangnya sama dengan nol (tahun)

$\mathrm{t}=$ Umur ikan (tahun)

\section{b. Parameter indeks kematian}

Koefisien kematian total "Z" dihitung dengan pendekatan kurva hasil tangkapan kumulatif. Metoda ini menghitung hubungan linier logaritmik frekwensi kumulatif dan logaritmik $(L \infty-L)$ yang dirumuskan dalam bentuk persamaan berikut :

$\ln (\mathrm{CN})=\mathrm{a}+(\mathrm{Z} / \mathrm{K}) \ln (L \infty-\mathrm{L})$

dimana : $\mathrm{CN}$ adalah frekuensi kumulatif, $\mathrm{Z}$ adalah estimasi koefisien mortalitas total dan $\mathrm{K}$ adalah koefisien pertumbuhan. Indeks $\mathrm{Z}$ diperoleh berdasarkan perhitungan

$\mathrm{Z}=\mathrm{K}^{*}$ slope.

Indeks kematian alami (M) dihitung dengan mengikuti persamaan empiris Pauly (1980) sebagai berikut : 
$\mathrm{LnM}=-0.0066-0.279 \mathrm{LnLoo}+0.6453 \mathrm{LnK}+0.4634 \mathrm{LnT} . . .(5)$

Indeks kematian akibat tekanan penangkapan $(\mathrm{F})$ dihitung melalui persamaan sebagai berikut:

$\mathrm{F}=\mathrm{Z}-\mathrm{M}$

\section{c. Tingkat Pemanfaatan}

(E) adalah F/Z

\section{d. Pendugaan ukuran panjang pertama kali matang $\operatorname{gonad}(\mathbf{L m})$}

Pendugaan panjang pertama kali matang gonad (length at first maturity) menggunakan rumus berdasarkan Udupa (1986),

$\mathrm{m}=\mathrm{Xk}+\mathrm{X} / 2-(\mathrm{XPi})$

Keterangan :

$\mathrm{m}=\log$ ukuran ikan saat pertama matang gonad

$\mathrm{Xk}=\log$ ukuran ikan dimana 100\% ikan sampel sudah matang

$\mathrm{X}=$ selang log ukuran (log size increment)

$\mathrm{Pi}=$ proporsi ikan matang pada kelompok ke-i

Rata-rata ukuran ikan pertama matang ovarium diperoleh dari nilai antilog $(\mathrm{m})$.

\section{e. Tingkat kematangan gonad (TKG)}

TKG diamati secara visual dengan cara melihat perubahan morfologi gonad sesuai dengan kriteria tingkat kematangan gonad berikut (Holden \& Raitt, 1974):

1. Tahap awal: Ovarium seperti benang, permukaan licin.

2. Tahap berkembang: Ovarium lebih besar, telur belum terlihat dengan mata.

3. Mulai matang: Gonad berwarna kuning, tampak butiran telur dan saluran darah.

4. Matang: Ovarium makin besar, bentuknya bening seperti agar, mengisi 1/2,2/3, sampai mencapai ukuran maksimum (fully developed gonad) yang siap memijah.

5. Memijah sampai spent: ovarium berkerut karena telur berangsur-angsur dilepaskan, sampai setengah dari ruang badan. Ovarium berisi sisa pelepasan butir-butir telur yang opaque dan yang matang.

Nilai Gonad Indeks tiap individu betina dihitung dengan rumus (Schaefer \& Orange in Batts, 1972):

$\mathrm{GI}=\mathrm{Wg} / \mathrm{L}^{3} * 10^{5}$

di mana:

GI = Gonad Indeks

$\mathrm{Wg}$ = berat gonad

$\mathrm{L} \quad=$ panjang ikan $(\mathrm{cm} \mathrm{FL})$

\section{HASIL DAN BAHASAN HASIL}

\section{Komposisi Hasil Tangkapan}

Ikan bentong di PP Kwandang ditangkap dengan menggunakan 4 alat tangkap yaitu mini purse seine (pajeko), bagan, payang dan pancing. Pada Gambar 2 terlihat bahwa ikan bentong lebih banyak tertangkap oleh bagan dibandingkan ketiga alat tangkap lainnya dengan hasil tangkapan berfluktuasi.

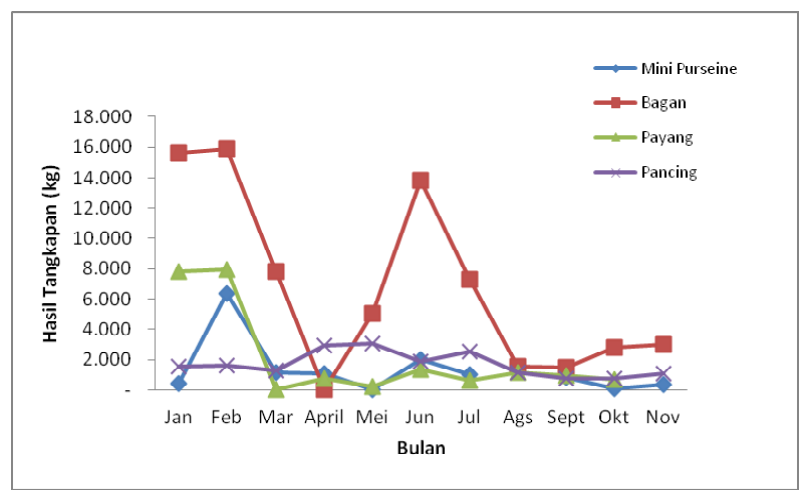

Gambar2. Hasil tangkapan bentong berdasarkan alat tangkap di PP Kwandang.

Figure 2. Catch of bigeye scad based on fishing gear in PP Kwandang.

\section{Parameter Populasi}

Hasil pengukuran sebaran frekuensi panjang sebanyak 314 ekor, dimulai pada nilai tengah (mean) 13,5 hingga 21 $\mathrm{cm}$ (Gambar 3). Gambar 3 memperlihatkan sebaran frekuensi panjang bulanan dari ikan bentong yang tertangkap. Dari Gambar tersebut terlihat bahwa ukuran ikan dengan ukuran lebih dari $19 \mathrm{~cm}$ banyak tertangkap pada bulan November.

Hasil analisis FISAT II menunjukkan koefisien pertumbuhan $(\mathrm{K})$ sebesar 0,76 per tahun dan panjang asimtotik $(L \infty)$ sebesar $24,7 \mathrm{~cm}$.

Hasil analisa menunjukkan bahwa laju kematian alami (M) ikan bentong sebesar 1,28 pertahun, laju kematian karena penangkapan sebesar 1,3 per tahun. Laju kematian total sebesar 2,63 pertahun dan laju eksploitasi E sebesar 0,51 per tahun (Tabel 1).

\section{Rasio Kelamin}

Rasio kelamin merupakan perbandingan jumlah ikan jantan dengan jumlah ikan betina dalam suatu populasi dimana perbandingan 1:1 yaitu $50 \%$ jantan dan $50 \%$ betina merupakan kondisi ideal untuk mempertahankan spesies (Effendie, 1997). Pada penelitian ini, jumlah contoh ikan bentong yang diamati sebanyak 314 ekor, dengan perbandingan jumlah jantan 156 ekor dan betina 158 ekor atau 1:1,02. 

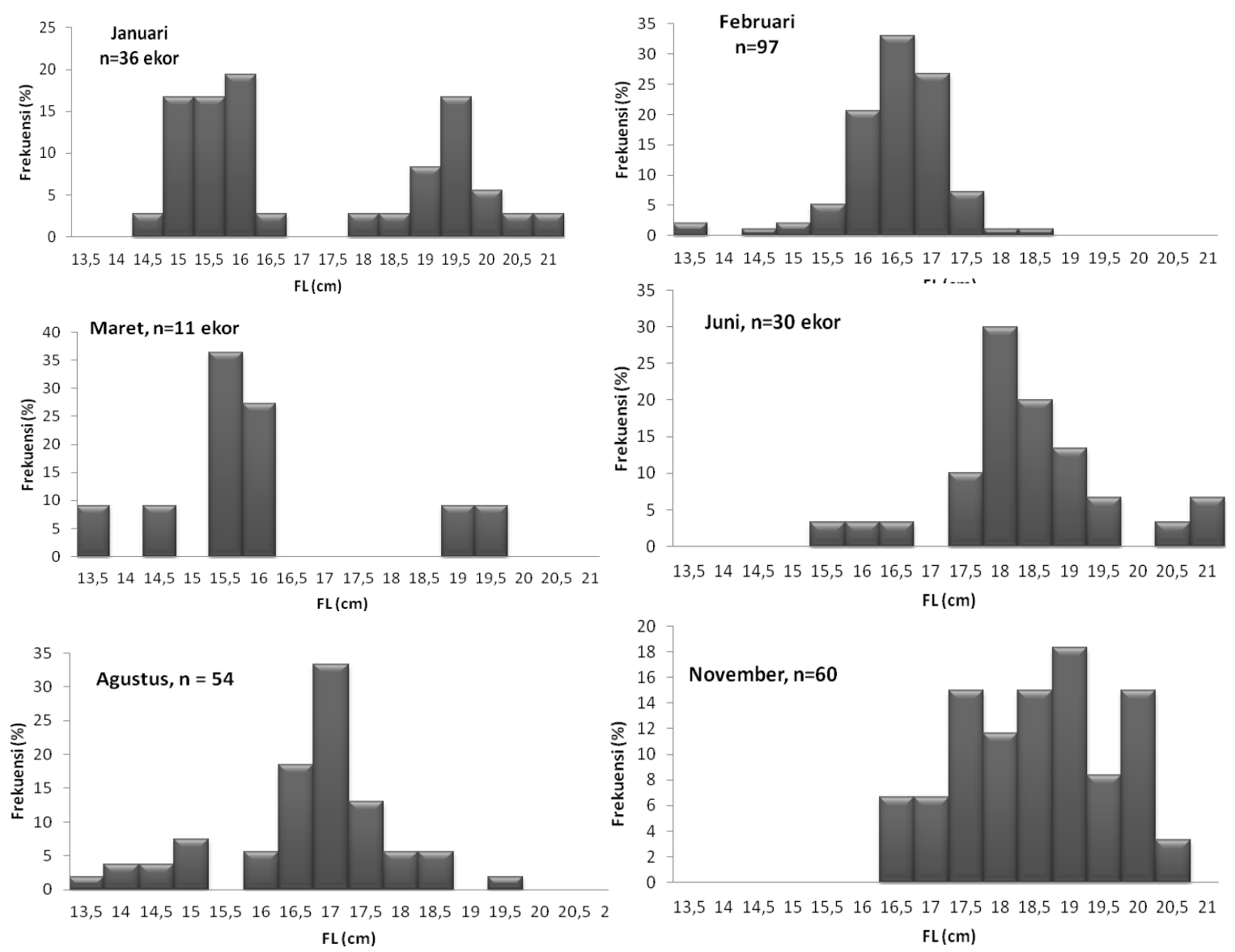

Gambar 3. Sebaran Panjang Cagak Ikan bentong di PP Kwandang tahun 2012.

Figure 3. Fork Length distribution of bigeye scad in PP Kwandang in 2012.

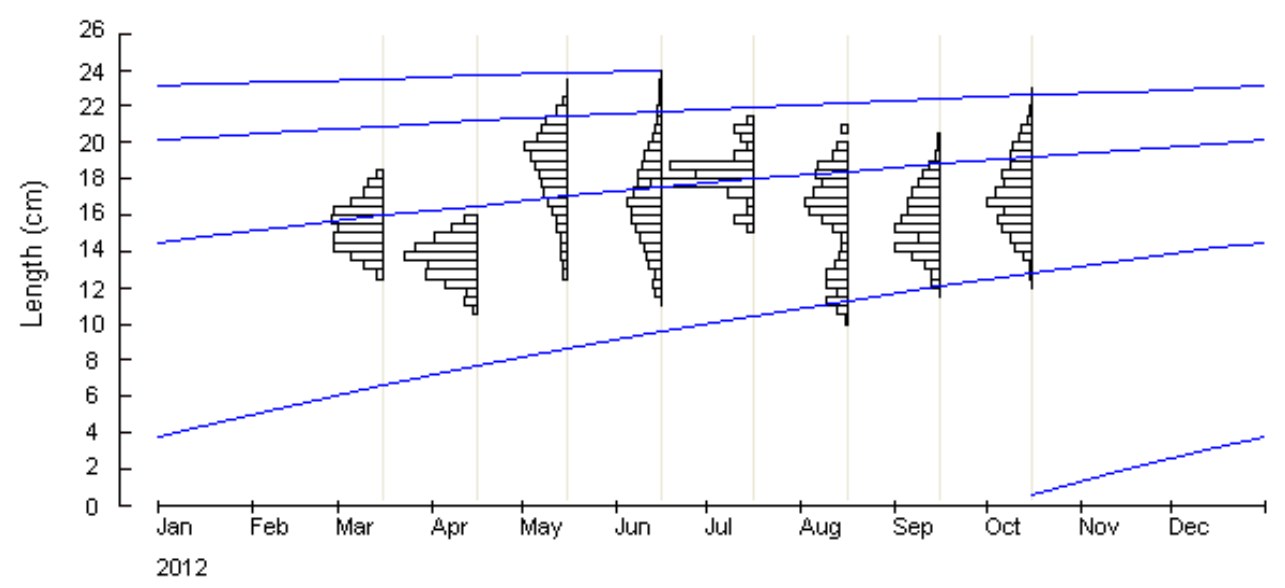

Gambar 4. Kurva pertumbuhan ikan bentong yang didaratkan di Pelabuhan Perikanan Kwandang tahun 2012. Figure 4. Growth Curve of bigeye scad landed at fishing harbor of Kwandang in 2012. 
Tabel 1. Parameter populasi ikan bentong yang didaratkan di Pelabuhan Perikanan Kwandang tahun 2012

Table 1. Population parameter of bigeye scad landed in fishing harbor of Kwandang 2012

\begin{tabular}{cc}
\hline Parameter & Nilai \\
\hline Lo $(\mathrm{cm})$ & 24,7 \\
K $\left(\right.$ tahun $\left.^{-1}\right)$ & 0,76 \\
Lm $(\mathrm{cm})$ & 19,5 \\
Lc $(\mathrm{cm})$ & 16,6 \\
Z & 2,63 \\
E & 0,51 \\
M & 1,28 \\
F & 1,3 \\
\hline
\end{tabular}

Tingkat Kematangan Gonad (TKG)

Komposisi TKG tiap bulan dapat dilihat pada Tabel 2. Dalam Tabel tersebut tampak bahwa, ikan betina dengan TKG 1 terdapat dalam jumlah yang relatif tinggi setiap bulannya, sedang ikan betina TKG 2 pada tiap bulan kecuali bulan Agustus persentasinya cenderung tinggi.

Tabel 2. Komposisi TKG ikan bentong betina dan ratarata GSI tiap bulan dari perairan Gorontalo Utara dalam pengamatan tahun 2012

Table 2. Monthly composition of Maturity Stage and average of Gonado Somatic Index in North Gorontalo in 2012

\begin{tabular}{ccccccc}
\hline & Jan & Feb & Mar & Jun & Ags & Nov \\
\hline TKG1 & 47 & 87 & 78 & 44 & 94 & 33 \\
TKG2 & 40 & 13 & 22 & 44 & 3 & 21 \\
TKG3 & 7 & 0 & 0 & 12 & 0 & 29 \\
TKG4 & 7 & 0 & 0 & 0 & 0 & 17 \\
TKG5 & 0 & 0 & 0 & 0 & 3 & 0 \\
\hline
\end{tabular}

Nilai rata-rata GSI yang rendah terjadi pada bulan Februari, Maret dan Agustus 2012 (Gambar 5). Sedangkan nilai rata-rata GSI yang tinggi terdapat pada bulan Januari dan November .

Persentase ikan yang Immature (TKG 1 dan TKG 2) dan yang Mature terdapat dalam Gambar 6. Dari Gambar tersebut terlihat bahwa ikan sampel bentong betina didominasi ikan yang Immature.

Pada bulan November 2012 terjadi proses pematangan gonad ikan bentong dimana ikan betina yang Immature maupun yang mature terdapat dalam hasil tangkapan. Terdapat sampel ikan TKG 4 yang sudah berkembang hampir sempurna menjelang pemijahan dan sudah mengandung cairan lumen.

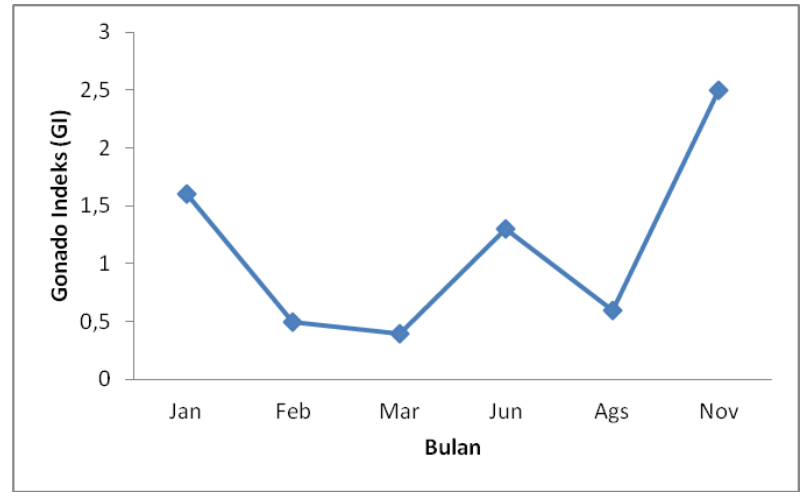

Gambar 5. Fluktuasi Indeks kematangan gonad ikan bentong tahun 2012.

Figure 5. Gonado Index of Bigeye scad in 2012.

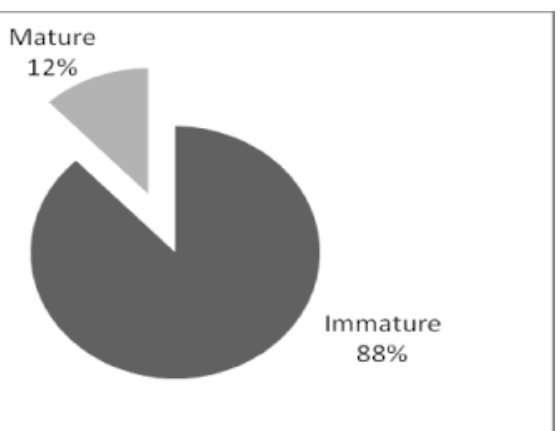

Gambar6. Persentase ikan bentong betina (Selar crumenophthalmus) belum matang dan matang dari perairan Gorontalo Utara dalam tahun 2012.

Figure 6. Percentation of female mature and immature of bigeye scad (Selar crumenophthalmus) from North Gorontalo waters, Sulawesi Sea in 2012 .

\section{BAHASAN \\ Parameter Populasi}

Nilai-nilai konstanta pertumbuhan ikan bentong dari perairan ini relatif tinggi (sekitar 0,8) karena pertumbuhan ikan pelagis kecil umumnya cepat. Nilai laju pertumbuhan $(\mathrm{K})$ yang diperoleh untuk ikan bentong adalah 0,76. Menurut Sparre \& Venema (1999) ikan dengan koefisien laju pertumbuhan $(\mathrm{K})$ yang tinggi mempunyai kecepatan pertumbuhan yang tinggi dan biasanya ikanikan tersebut memerlukan waktu yang singkat untuk mencapai panjang maksimumnya. Sementara itu, ikan dengan laju koefisiennya rendah, membutuhkan waktu yang lama untuk mencapai panjang maksimumnya, maka cenderung berumur panjang.

Ukuran pertama kali matang gonad ikan bentong adalah $\mathrm{Lm}=19,5$. Nilai ini lebih besar daripada ikan bentong yang tertangkap di laut Jawa yaitu $\mathrm{Lm}=18,7$ (Atmaja et 
al., 1995). Sementara itu ukuran ikan pertama kali tertangkap yaitu $\mathrm{Lc}=16,6 \mathrm{~cm}$. Nilai Lc ini lebih kecil daripada $\mathrm{Lm}$, hal ini berarti bahwa ikan yang tertangkap belum melewati ukuran pertama kali matang gonad.

Laju kematian alami (M) ikan bentong sebesar 1,28 pertahun, laju kematian karena penangkapan $(\mathrm{F})$ sebesar 1,3 per tahun. Nilai kedua laju kematian tersebut seimbang, sehingga diperkirakan stock ikan yang dimanfaatkan di perairan Kwandang ini sudah optimal. Gulland (1971) in Sparre \& Venema (1999) menyatakan bahwa dalam stok yang dieksploitasi optimal maka laju mortalitas penangkapan (F) sama dengan laju mortalitas alami (M) atau laju eksploitasi (E) sama dengan 0,5. Atmaja \& Nugroho, (2004) menambahkan bahwa kematian ikan akibat adanya penangkapan adalah berbanding lurus dengan upaya penangkapan dan kemampuan tangkap yang artinya bahwa kenaikan kematian akibat penangkapan akan diikuti dengan kenaikan upaya penangkapan. Nilai tingkat pemanfataan (E) ikan bentong pada saat penelitian sebesar 0,51 hal ini berarti bahwa stok ikan yang dieksploitasi relatif optimal. Nilai tingkat pemanfaatan di perairan ini lebih besar daripada yang ditemukan di perairan Maluku yaitu 0,27 (Syam, 2006). Hal ini menunjukkan bahwa tindakan pengelolaan harus dilakukan secara hati-hati dengan cara pembatasan jumlah alat tangkap bagan dan pembatasan ukuran mata jaring agar ikan yang tertangkap lebih besar dari Lm sehingga kelestarian sumberdaya ikan bentong dapat tetap berkelanjutan.

\section{Rasio Jenis Kelamin}

Rasio jenis kelamin ikan bentong (Selar crumenophthalmus) antara ikan jantan dan betina pada penelitian ini adalah 1:1,02. Hal ini menunjukkan bahwa rasio kelamin ikan bentong masih seimbang, artinya peluang untuk bereproduksi masih tinggi dan masih dalam kondisi ideal untuk mempertahankan spesies (Effendie, 1997). Keseimbangan disebabkan ikan jantan dan betina keduanya aktif sehingga peluang tertangkapnya kedua jenis ikan tersebut seimbang. Keseimbangan jumlah ikan jantan dan betina mengindikasikan bahwa satu ikan bentong jantan akan membuahi satu ikan bentong betina (Senen et al, 2011) Rasio kelamin ini tidak berbeda jauh dengan rasio kelamin hasil penelitian Zamroni\&Suwarso (2011) di perairan Laut Banda dan penelitian yang dilakukan oleh Widodo et al. (1993) di perairan Laut Jawa.

\section{Tingkat Kematangan Gonad}

Ikan bentong betina yang mulai matang (TKG 3) dan yang matang (TKG 4) hanya terdapat pada bulan-bulan tertentu dalam jumlah yang relatif rendah. Ikan betina TKG 5 (selesai mijah) hampir tidak dijumpai kecuali pada bulan Agustus dengan persentase yang rendah.
Berdasarkan tingginya GSI rata-rata pada bulan November-Januari dan komposisi TKG maka pada November-Januari diduga akan terjadi pemijahan. Menurut Atmaja et al. (1995) puncak musim pemijahan Selar crumenophthalmus di Laut Jawa yang tertangkap purse seine diduga berlangsung sekitar musim barat (Desember-Februari) dan menurut Zamroni dan Suwarso nilai indeks gonad Selar crumenophthalmus dengan nilai yang lebih tinggi terjadi pada musim timur (Juni-Agustus).

\section{KESIMPULAN}

Pemanfaatan ikan bentong di perairan KwandangGorontalo Utara terindikasi telah mencapai tingkat optimum dengan nilai E sebesar 0,51, hal ini didukung oleh laju kematian akibat penangkapan yang relatif sama dengan kematian alami. Oleh BEL karena itu diperlukan pengelolaan yang hati-hati dan bertanggungjawab yaitu salah satunya dengan adanya pembatasan penambahan bagan dan ukuran mata jaring. Rasio kelamin ikan bentong relatif seimbang. Ikan yang banyak tertangkap sebagian besar masih belum matang (TKG I) dan masih di bawah Lm sehingga belum layak tangkap. Musim pemijahan ikan bentong diduga terjadi pada bulan November-Januari.

\section{PERSANTUNAN}

Tulisan ini merupakan kontribusi dari kegiatan Inisiasi Implementasi EAFM di WPP RI T.A. 2012, di Pusat Penelitian Pengelolaan Perikanan dan Konservasi Sumberdaya Ikan - Jakarta.

\section{DAFTAR PUSTAKA}

Atmaja \& Nugroho, 2004. Karakteristik parameter populasi ikan siro (Amblygaster sirm) dan model terapan Beverton dan Holt di Laut Natuna dan sekitarnya. JPPI. 10 (4): ...

Atmaja, S. B., B. Sadhotomo, \& Suwarso. 1995.Reproduction of main small pelagic species in Java Sea. Workshops Biology, Dynamic, and Exploitationof Small Pelagic in Java Sea. Jakarta.

Batts, B. S. 1972. Sexual maturity, fecundity, and sex ratio of skipjack tuna (K. pelamis Linn.) in North Carolina Waters. Trans. Amer. Fish. Soc. 101 (4): 626-637.

Effendie, I. M. 1997. Biologi Perikanan. Yayasan Dewi Sri.

FISAT II. 2004. FAO - ICLARM Fish Stock Assessment Tools Version 1.13. Rome.

Gulland, J.A. 1971. The Fish Resources of the Oceans. Fishings News (Books) Ltd. Surrey, England. 209 p. 
Holden, M. J., \& D. F. S. Raitt. 1974. Manual of fisheries science. Part 2: Methods of recources investigation and their application. FAO Fish. Tech. Pap. (115): 214 p.

Pauly, D. J. Ingles \& R. Neal. 1984. Application to shrimp stocks of objective methods for the estimation of growth, mortality, and recruitment related parameters from length frequency data (ELEFAN I and II). In Penaeid Shrimp-Their Biology \& Management. Fishing News Book Limited. Farnham-Surrey-England: 220-234.

Senen, B., Sulistiono \& I. Muchsin. 2011. Beberapa Aspek Biologi Ikan Layang Deles (Decapterus macrosoma) Di Perairan Banda Neira, Maluku . Prosiding Seminar Nasional. Pengembangan Pulau-pulau Kecil 2011. 52$60 \mathrm{Hal}$.

Sparre, P. \& S.C. Venema, 1999. Introduksi pengkajian stok ikan tropis. Buku 1. Manual. FAO Fish. Tech. Pap

Suwarso, A. Kuswoyo \& M. Fauzi. . 2013. Ekspoitasi Ikan Pelagis Kecil di Laut Sulawesi. Bunga Rampai Status Pemanfaatan sumber Daya Ikan di perairan Laut Jawa dan Laut Sulawesi. BPPL.
Syam, A.R.2006. Parameter Sotk dan Laju Eksploitasi Ikan Kawalinya (Selar crumenophthalmus) di Peraian Maluku. Prosiding Seminar Nasional Ikan IV. Jatiluhur, 29-30 Agustus 2006.

Udupa, K. S. 1986. Statistical method of estimating the size of first maturity in fish. Fishbyte ICLARM. Manila.4 (2). 8-1.

Widodo, J., Suwarso, \& H. Suryono. 1993. Biologi reproduksi dan perikanan selar bentong, Selar crumenophthalmus (Carangidae), di Laut Jawa. JurnalPenelitian Perikanan Laut. 72: 1-9.

Widodo, J. 1989. Roproductive biology and harvesting strategy of indian scad, Decapterus russelli (Ruppell, 1830), (Pisces: Carangidae) of the Java sea. Jurnal Penelitian Perikanan Laut. 53: 89-96.

Zamroni, A \& Suwarso. 2011. Studi Tentang Biologi Reproduksi Beberapa Species Ikan Pelagis Kecil di perairan Laut Banda. BAWAL. 3 (5): 337-344. 